\title{
The EMSO-ERIC Pan-European Consortium: Data Benefits and Lessons Learned as the Legal Entity Forms
}

\author{
Best Mairi M. R. ${ }^{1,{ }^{*}}$, Favali Paolo ${ }^{1}$, Beranzoli Laura ${ }^{1}$, Blandin Jerome ${ }^{2}$, Cagatay Namik M. ${ }^{3}$, \\ Cannat Mathilde ${ }^{2}$, Jose Danobeitia Juan ${ }^{4}$, Delory Eric ${ }^{4}$, De Miranda Jorge M. A. ${ }^{5}$, \\ Del Rio Fernandez Joaquin ${ }^{4}$, De Stigter Henko ${ }^{6}$, Gillooly Mick ${ }^{7}$, Grant Fiona ${ }^{7}$, Hall Per O. J. ${ }^{8}$, \\ Hartman Susan ${ }^{9}$, Hernandez-Brito Joaquin ${ }^{4}$, Lanteri Nadine ${ }^{2}$, Mienert Juergen ${ }^{10}$, Oaie Gheorge ${ }^{11}$, \\ Piera Jaume ${ }^{4}$, Radulescu Vlad ${ }^{12}$, Rolin Jean-Francois ${ }^{2}$, Ruhl Henry A. ${ }^{9}$, Waldmann Christoph ${ }^{13}$ \\ ${ }^{1}$ EMSO Italia, JRU, INGV, Rome, Italy. \\ ${ }^{2}$ CNRS, IPGP, IFREMER, F-75700 Paris, France. \\ ${ }^{3}$ Istanbul Tech Univ, Eastern Mediterranean Ctr Oceanog \& Limnol TU EMC, Istanbul, Turkey. \\ ${ }^{4}$ Univ Politecn Cataluna, Ocean Platform Canary IsI PLOCAN, UTM CSIC, E-08028 Barcelona, Spain. \\ ${ }^{5}$ Portuguese Sea \& Atmosphere Inst IPMA, Lisbon, Portugal. \\ ${ }_{7}^{6}$ Stichting Koninldijk Nederlands Inst Onderzoek Ze, Utrecht, Netherlands. \\ ${ }^{7}$ Marine Inst IMI, Galway, Ireland. \\ 8 Univ Gothenburg, UGOT, Gothenburg, Sweden. \\ ${ }^{9}$ NOCS, Liverpool, Merseyside, England. \\ ${ }_{11}^{10}$ Univ Tromsoe UIT, Tromso, Norway. \\ ${ }^{11}$ HCMR, Athens, Greece. \\ 12 Inst Natl Cercetare, Dezvoltare Pentru Geol \& Geoecol Marina GeoEcoMar, Bucharest, Romania. \\ ${ }^{13}$ German Marine Res Consortium KDM, Berlin, Germany.
}

* Corresponding author : Mairi M. R. Best, email address : mmrbest.interimoffice@emso-eu.org

\begin{abstract}
:
The European Multidisciplinary Seafloor and water-column Observatory (EMSO) European Research Infrastructure Consortium (ERIC) provides power, communications, sensors, and data infrastructure for continuous, high-resolution, (near-)real-time, interactive ocean observations across a multidisciplinary and interdisciplinary range of research areas including biology, geology, chemistry, physics, engineering, and computer science, from polar to subtropical environments, through the water column down to the abyss. Eleven deep-sea and four shallow nodes span from the Arctic through the Atlantic and Mediterranean, to the Black Sea. Coordination among the consortium nodes is being strengthened through the EMSOdev project $(\mathrm{H} 2020)$, which will produce the EMSO Generic Instrument Module (EGIM). Early installations are now being upgraded, for example, at the Ligurian, Ionian, Azores, and Porcupine Abyssal Plain (PAP) nodes. Significant findings have been flowing in over the years; for example, high-frequency surface and subsurface water-column measurements of the PAP node show an increase in seawater pCO2 (from $339 \mu$ atm in 2003 to $353 \mu$ atm in 2011) with little variability in the mean air-sea CO2 flux. In the Central Eastern Atlantic, the Oceanic Platform of the Canary Islands open-ocean canary node (aka ESTOC station) has a long-standing time series on water column physical, biogeochemical, and acidification processes that have contributed to the assessment efforts of
\end{abstract}


the Intergovernmental Panel on Climate Change (IPCC). EMSO not only brings together countries and disciplines but also allows the pooling of resources and coordination to assemble harmonized data into a comprehensive regional ocean picture, which will then be made available to researchers and stakeholders worldwide on an open and interoperable access basis.

Keywords : Ocean Observatory Consortium, Europe, geohazards, Climate change, ecosystems 


\section{Introduction}

The European Multidisciplinary Seafloor and water-column Observatory (EMSO) is a panEuropean distributed research infrastructure, composed of fixed-point open ocean observatory nodes, whose aim is to provide coherent long-term data sets to study and monitor European seas. Changes relating to resource availability, climate change, habitat destruction, and geo-hazards have increased society's need for an improved understanding of the driving factors and the effects of such changes. EMSO includes polar to sub-tropical marine environments, from the surface down to the abyss. 11 deep sea and 4 shallow nodes span from Arctic through the Atlantic and Mediterranean, to the Black Sea (Figure 1). EMSO observation data is collected from the ocean's surface, through the water column to sub-seafloor across geo-hazard, physical, biogeochemical and ecological themes, with various emphases depending on location.

\section{A New Type of Research Infrastructure}

EMSO is forging ahead through the next challenge in Earth-Ocean Science: How to coordinate ocean data acquisition, analysis and response across provincial, national, regional, and global scales. Contrary to other environmental infrastructures which have been established for decades (e.g. seismic and satellite systems), Ocean Observatories are a recent development. They are also inherently multidisciplinary. While this can increase the challenge of harmonizing them at an international scale, it also means there is the opportunity to do so before designs and protocols diverge too far.

\section{History and Linkages}

It is important to appreciate that the various national initiatives that come together to form distributed European Research Infrastructure Consortia (ERICs) have already experienced 
the challenges of any nationally supported infrastructure, including in some cases federated provinces, contributions of more than one institute (academic and/or governmental) and/or nation to an infrastructure, etc. Potential ERIC's which were placed on the European Strategy Forum on Research Infrastructures (ESFRI, www.esfri.eu) Roadmap were beyond this criteria - there was a demonstrated need for a pan-European Infrastructure in the given domain. With EMSO on this Roadmap, as an early example of a necessarily Distributed Infrastructure, the EMSO Preparatory Phase (FP7) project led to the Interim Phase (involving 13 countries) of forming the legal entity: the EMSO-ERIC). Legally founded in 2016, the founding members of the EMSO-ERIC include Italy (Host Nation), Greece, U.K., France, Ireland, and Portugal, with Spain, Romania, and Turkey traversing their national membership processes, and Germany, Sweden, Norway, and the Netherlands continuing to maintain contact while they proceed through national prioritization processes. National membership is open to growth. Marine Science communities at national levels are also progressively joining together to network, share and exploit their research infrastructures, efforts and skills in support of EMSO. It is particularly important to have this national-level coordination as the ERIC structure is according to national membership. For example, Italian and French communities have established joint research groups, namely EMSO Italia and EMSO France, gathering research institutions and universities under the leadership of INGV in Italy and Ifremer and CNRS in France. These research groups help to increase awareness of the EMSO opportunities and broaden the scientific user base. At the regional to global scale, the open user community is supported through ESONET-Vi (European Seafloor 
Observatory NETwork - The Vision, visobservatories.webs.com), following on the extensive scientific community planning contributions of the ESONET-NoE (FP6) project. Along with EMSO-ERIC and ESONET-Vi, the FixO3 project (FP7) follows on the efforts of ESONET-NoE and EuroSITES to pull together the efforts of the European science community towards fixed point ocean observatories. The FixO3 project strengthens in particular the EMSO Nodes and Regional Teams, operating at their national levels and continues the development of the concept of a "label" for assessed technologies and services.

The broader target of coordination among Environmental Research Infrastructures at the regional to global scale benefits from progress through the CoopEUS, COOP+, ENVRI, and ENVRIplus coordination projects. EMSO also represents a fundamental contribution to the long-term vision of the European Ocean Observing System (EOOS). It will contribute in situ observations for the Global Monitoring for Environment and Security Initiative, COPERNICUS, and is aligned with the challenges and key priorities of Horizon 2020 and, in particular, with the Marine Strategy Framework Directive (MSFD). The data collected by EMSO will support policy and legislation of organizations such as the Intergovernmental Panel on Climate Change (IPCC), the United Nations Environment Programme (UNEP) and the Group on Earth Observation (GEO).

\section{Infrastructure Evolution}

EMSO open ocean observatory locations were identified according to the scientific priorities of the European marine science community, through multiple coordination projects. These locations were selected because their ongoing key natural processes 
require long-term monitoring to understand their dynamics at the regional scale. EMSO spans from polar to sub-tropical climatic zones and from the open ocean (Atlantic) to closed basins (Mediterranean, Sea of Marmara and Black Sea) thus offering a broad spectrum of study areas across diverse environments. Tests sites are also integral parts of the observatory network and they are fundamental facilities for testing devices (software and hardware) to be incorporated into EMSO nodes.

The present operational modes of the nodes include both cabled and autonomous observatories, both with their benefits: while continuous data flow is provided by cabled nodes that receive power and communications directly from land, autonomous observatories are powered with long-lasting batteries, store the acquired data locally, and provide greater flexibility in placement. Some of the latter periodically transfer some data via acoustics or cable communications from the deep ocean to a surface buoy, which in turn sends them to land stations by satellite.

EMSO Nodes have been developed in response to national to regional requirements. As such, they were designed and developed fit-to-purpose in a naturally distributed fashion. They have already experienced the support and growth challenges of any nationally supported infrastructure. The current challenge is the coordination of these distributed nodes, purpose built to address different societal concerns in the sea, to find the points of commonality where the whole may actually be greater than the sum of the parts. This does not mean homogenization and standardization across the board - nodes designed for key ocean carbon monitoring may find tsunami monitoring a distant concern; those designed for tsunami monitoring as a proximal threat to large populations cannot drop that function to mimic nodes that are not threatened in this way... 


\section{EMSO Generic Instrument Module (EGIM)}

That said, certain "essential ocean variables (EOV)" are being converged upon and are informing the development of standardized platforms. This process started in the surface ocean, as an extension of the "essential climate variables (ECV)" concept, and therefore continues to require further input from the full water column and seafloor - over $90 \%$ of the living space of the planet. An example of addressing the need for this is the EMSOdev (H2020) project which is developing the EMSO Generic Instrument Module (EGIM). Coordination among the consortium nodes through this project will produce standardized observations of temperature, pressure, salinity, dissolved oxygen, turbidity, chlorophyll fluorescence, currents, passive acoustics, $\mathrm{pH}, \mathrm{pCO} 2$, and nutrients. It also strengthens the consortium to operate as a whole greater than the sum of the parts, with each taking on different roles within the project; for example the OBSEA Observatory at the Catalan Node will play its role as an important shallow water test node within EMSO. This will create an innovative, standardized, and harmonized system of scientific measurements and time series. It will also strengthen Europe's role as a key player in the development of the International Oceanographic Commission-Global Ocean Observing System (GOOS). As the EGIM is open and modular, EMSO ERIC can also offer it as a service to Industry for "client specific" purposes. It can be used, for instance, for impact assessment of marine renewable energy concepts; for resource evaluation of marine turbines; for monitoring oil and gas spill accidents; for impact assessment of marine mineral resource extraction fields; for subsea monitoring of sediment debris flows (current and turbidity); for geohazard monitoring of oil and gas production fields; and for monitoring fish behavior in key areas. 


\section{Node Upgrades}

Early node installations are now being upgraded. For example, in October 2015, EMSOFrance deployed a second cable and junction box serving the Ligurian Sea Node in order to monitor slope stability offshore Nice (Figure 2). In 2016, the EMSO Azores Node receives a major upgrade that will double its observing capacity. Also in 2016, the Ionian Sea Node's Capo Passero site will be installed (southernmost in the consortium) and the Catania site will be upgraded.

\section{Data Impact}

Significant findings have been flowing in over the years, for example:

\section{Porcupine Abyssal Plain Node}

At the PAP Node in the northeast Atlantic (49N, 16:5W), we aim to understand the controls of biogeochemical fluxes in the open ocean to the deep seafloor and detect climate driven trends from natural variability in the North Atlantic, including biomass and community structure over time, C sequestration, remineralization estimates of respiration for understanding the effect of episodic events, trace pulse events from climate and surface ocean to seafloor influences, to contribute in situ data for understanding global change. High frequency surface and subsurface water column measurements, using autonomously deployed instruments, show an increase in seawater p(CO2) (from $339 \mu$ atm in 2003 to $353 \mu$ atm in 2011) with little variability in the mean air-sea CO2 flux. Year to year variations in the timing and intensity of the spring bloom occurs despite similar winter physical conditions (temperature and MLD) (Figure 3; Hartmann et al. 2014). Over 225 
Best et al. - EMSO-ERIC

peer-reviewed papers have been published from the PAP time-series since 1975 (noc.ac.uk/pap/publications).

\section{Koljo Fjord Node}

In this Swedish fjord, carbon cycling processes are tracked in high resolution in a coastal transition zone system rather than the deep sea of PAP. In this case, a cabled underwater observatory with more than 30 sensors delivering data in real-time was used to study the dynamics of the upper pelagic carbonate system from September to April during two consecutive years (2011-2012 and 2012-2013). In the dynamic upper ca $15 \mathrm{~m}$ of the water column, salinity and temperature varied by up to 10 and 20 degrees $C$ throughout the recorded periods, respectively. Partial pressure of $\mathrm{CO} 2(\mathrm{pCO}(2))$, measured with newly developed optical sensors (optodes) at three water depths (5, 9.6 and $12.6 \mathrm{~m})$, varied between 210-940 mu atm, while 0-2 varied between 80-470 mu mol/L. Distinctive shortterm variations of $\mathrm{pCO}(2)$ and $0-2$ were induced by either tidal oscillations, wind-driven water mass transport in the mixed layer or occasional transport of deep-basin water from below the thermo/halodine to the surface layer. Intensified air-sea gas exchange during short storm events was usually followed by stabilization of gas-related parameters in the water column, such as $0-2$ concentration and $\mathrm{pCO}(2)$, on longer time-scales characteristic for each parameter. Biological processes including organic matter degradation in late summer/autumn and primary production in early spring were responsible for slower and gradual seasonal changes of $\mathrm{pCO}(2)$ and $0-2$. Net primary production (NPP) rates in the Koljo Fjord were quantified to be 1.79 and $2.10 \mathrm{~g} \mathrm{C} \mathrm{m(-2)} \mathrm{during} \mathrm{the} \mathrm{spring} \mathrm{bloom} \mathrm{periods}$ in 2012 and 2013, respectively, and ratios of 02 production:DIC consumption during the 
same periods were estimated to be $-1.21+/-0.02$ (at $5 \mathrm{~m}$ depth in 2013), $-1.51+/-0.02$ (at $12.6 \mathrm{~m}$ in 2012) and $-1.95+/-0.05$ (at $9.6 \mathrm{~m}$ in 2013) (Atamanchuk et al. 2015).

\section{Azores Node}

The EMSO-Azores fixed-point observatory aims to acquire, process and model time-series data to better understand water column and ecosystem dynamics at and above mid-ocean ridge hydrothermal vents. These ecosystems are controlled both by km-scale hydrothermal circulations powered by magmatic heat, and by smaller-scale near-surface fluid circulations and mixing between seawater and hydrothermal fluids. Currents in the water column near the seafloor also affect these fluxes. This fundamental knowledge is a prerequisite to assess faunal response to other potential sources of perturbation of the deep sea environments, such as climate change, deep sea mining or hydrocarbon exploitation. Over the last few years, we have shown that the structure and composition of the dominant faunal assemblages at Lucky Strike are controlled by their position in the mixing gradient (Sarradin et al. 2009, Cuvelier et al. 2009). Chemical processes in this gradient control the speciation of sulfide and metallic compounds (Waeles et al. submitted; Aumond, 2013). Environmental conditions also influence not only the microbial production via the availability of energy sources (de Busserolles et al. 2009) and the proportion of endosymbionts in the mussel Bathymodiolus azoricus (Halary et al. 2008) but also the availability of toxic compounds and oxygen (Cosson et al. 2008, Sarradin et al. 2009, Martins et al. 2011; Aumond, 2013). While the spatial distribution of the hydrothermal fauna is relatively well documented, only a few data are available on the temporal dynamics of hydrothermal ecosystems (Glover et al. 2010). Most studies concern recolonisation processes on fast spreading ridges following catastrophic events (Shank et 
al. 1998 ; Tsurumi and Tunnicliffe 2001 ; Marcus et al. 2009) and rely on yearly-cruises rather than on time-series analyses (Sarrazin et al. 1997 ; Copley et al. 2007 ; Cuvelier et al. 2011; Shank et al. 1998).

\section{Canary Islands PLOCAN Node}

In the Central Eastern Atlantic, the PLOCAN open-ocean Node (a.k.a ESTOC station) has a long-standing timeseries on surface and water column variables, most notably on water column physical, biogeochemical and acidification processes. Acquired data have contributed to the assessment efforts of the Intergovernmental Panel on Climate Change (IPCC) and the characterization of oceanic processes in the North Atlantic subtropical gyre.

\section{Ionian and Hellenic Nodes}

The Ionian and Hellenic Sea Nodes are examples of systems that first and foremost feed into national and regional seismic and tsunami geohazard risk systems. That said, they, like all fixed ocean observatories, provide power and communications, and therefore have accommodated other instruments and applications of their data. For example, the high resolution hydrophone data from the Ionian node is providing unparalleled information about marine mammals passing through these key marine straights.

\section{Lessons Learned}

- Ocean Observatories are a recent development. They are also inherently multidisciplinary. While this can increase the challenge of harmonizing them at an international scale, it also means there is the opportunity to do so before designs and protocols diverge too far. 
- In distributed environmental research infrastructures, the challenge is the coordination of distributed nodes, purpose built to address different societal concerns, to find points of commonality where the whole may actually be greater than the sum of the parts. This does not mean homogenization and standardization across the board.

- It is important to appreciate that the various national initiatives that come together to form distributed European Research Infrastructure Consortia (ERICs) have already experienced the challenges of any nationally supported infrastructure, including in some cases federated provinces, contributions of more than one institute (academic and/or governmental) and/or nation to an infrastructure, etc. Therefore, it is possible to move past national politics to form regional to global cooperation.

EMSO is forging ahead through the next challenge in Earth-Ocean Science: How to coordinate ocean data acquisition, analysis and response across provincial, national, regional, and global scales.

\section{Acknowledgements}

The authors acknowledge the support of all sponsors of ... 


\section{References}

Best, M.M.R., Favali, P., Beranzoli, L., Cannat, M., Çağatay, M.N., Dañobeitia, J.J., Delory, E., de Stigter, H., Ferré, B., Gillooly, M., Grant, F., Hall, P.O.J., Lykousis, V., Mienert, J., de Miranda, J.M.A., Oaie, G., Radulescu, V., Rolin, J.-F., Ruhl, H.A., Waldmann, C., 2014. EMSO: A distributed infrastructure for addressing geo-hazards and global ocean change. Oceanography 27(2):167-169, doi:http://dx.doi.org/10.5670/ oceanog.2014.52.

Favali, P., L. Beranzoli, M.M.R. Best, J.R. Delaney, A. De Santis, A.W. Edwards, K. Suyehiro 2015. Concluding Remarks: Perspectives and long-term vision. Chapter 26 in Seafloor Observatories: A New Vision of the Earth from the Abyss, P. Favali, A. de Santis, and L. Beranzoli, (Eds.), Springer Praxis Books.

S. E. Hartman, Z.-P. Jiang, D. Turk, R. S. Lampitt, H. Frigstad, and C. Ostle, 2014.

Biogeochemical variations at the Porcupine Abyssal Plain Sustained Observatory in the northeast Atlantic Ocean, from weekly to inter-annual time scales. Biogeosciences Discuss., 11, 1-25.

Atamanchuk, D., M. Y. Kononets, P. J. Thomas, J. Hovdenes, A. Tengberg, P. Hall 2015. Continuous long-term observations of the carbonate system dynamics in the water column of a temperate fjord. Journal of Marine Systems 148(2015) 272 284.

Ruhl... 
Best et al. - EMSO-ERIC

\section{Figure Legends}

Figure 1. Map of EMSO nodes. EMSO includes polar to sub-tropical environments, from the surface down to the abyss. 11 deep sea and 4 shallow nodes span from Arctic through the Atlantic and Mediterranean, to the Black Sea.

Figure 2. EMSO-Ligurian Node, Final tests prior to deployment of the new junction box (CIfremer / Olivier Dugornay)

Figure 3. In situ 30m PAP-SO data (blue circles) from 2003 to 2005 and 2010 to 2012 and 5m Ship of Opportunity (SOO) data (red squares) with vertical lines to represent the start of each year showing: (a) p(CO2); (b) chlorophyll a concentration; (c) weekly-averaged nitrate concentration. Hartman et al. 2015 


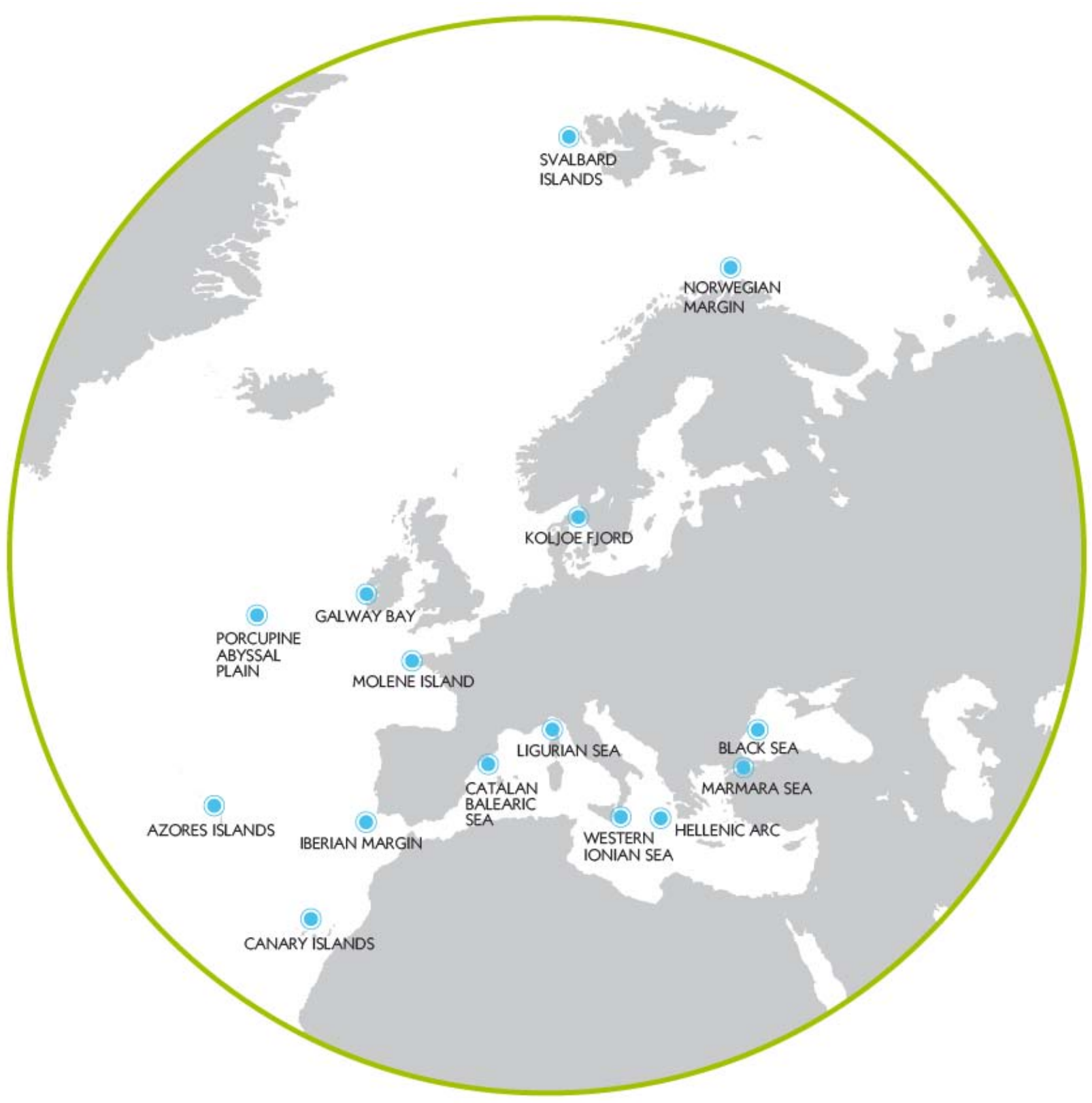

Figure 1. 
Best et al. - EMSO-ERIC

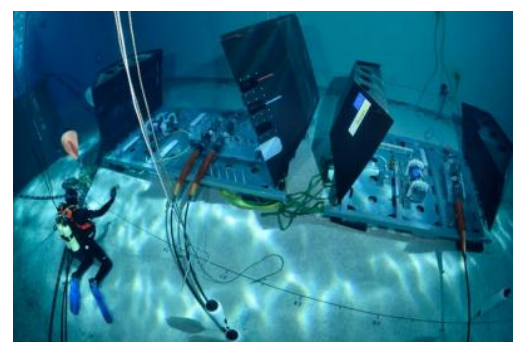

Figure 2. 
a)

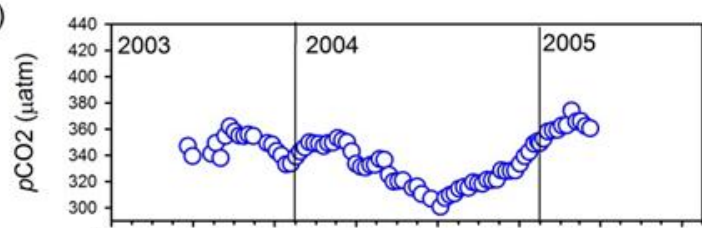

b)

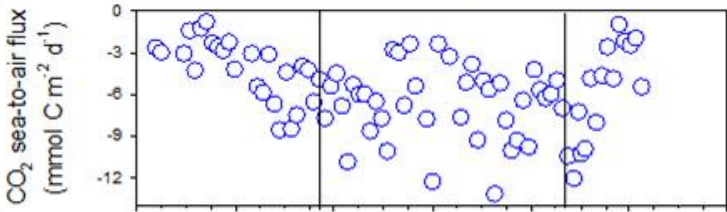

c)

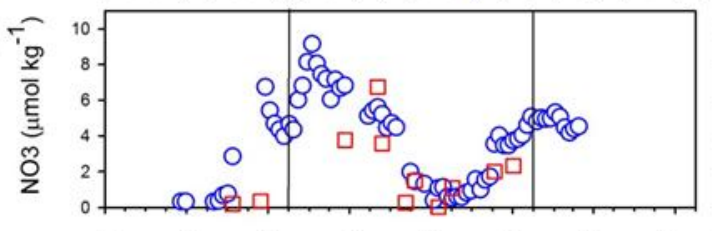

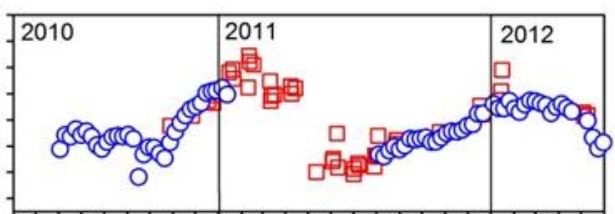
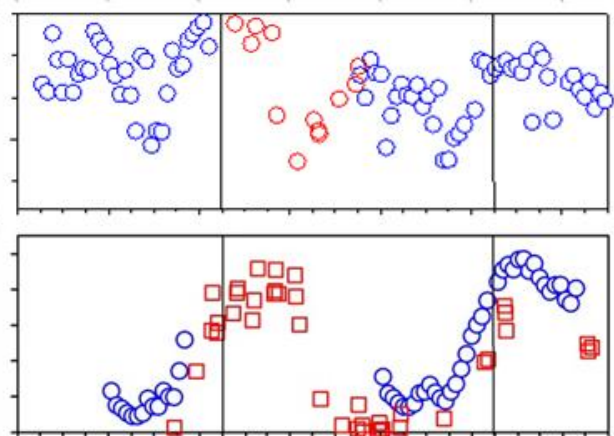

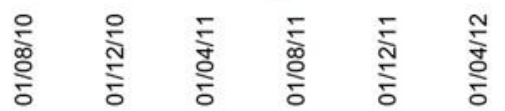

Figure 3 